\title{
D 0 PERIGOS DO OUTRO: MINORIAS RELIGIOSAS E RESISTÊNCIA TRIDENTINA DOS EXORCISTAS ITALIANOS
}

\author{
Tiago Pires \\ Universidade Estadual de Campinas \\ Campinas - SP - Brasil
}

Orcid: https://orcid.org/0000-0003-2351-5165

\section{Introdução $^{1}$}

Os movimentos de resistência à pluralidade religiosa perpassam toda a história da Igreja Católica, que abarca desde o início a dificuldade em dialogar com as alteridades nas formas de crer. Para o presente artigo, temos como recorte a conjuntura que se formou após os desdobramentos do Concílio Vaticano II (1962-1965), com atenção especial à sociedade italiana a partir dos anos 1980. Dentre os variados movimentos conservadores contemporâneos da Igreja Católica, optamos por analisar a vertente que se ocupa com a prática de "expulsão do mal": os exorcistas. De que forma se configuram as respostas dadas pelos exorcistas italianos a partir dos anos 1980 à pluralidade religiosa e cultural que começou a se formar na Itália naquele momento? Em que medida essa resposta se concatena tanto em um projeto de retomada do exorcismo (dimensão teológica) quanto na dificuldade em aceitar os diálogos com a modernidade e com a multiplicidade das culturas religiosas no território italiano?

Nesse sentido, entendemos a rivalidade entre exorcistas e minorias religiosas na Itália como um embate que está para além do campo teológico-religioso, configurando-se também como uma disputa política por espaço social, credibilidade (De Certeau 1998) e retomada de uma Igreja centralizante e com mais autoridade dian- 
te da sociedade. Para tanto, optamos por utilizar a categoria tridentina para delimitar esse projeto teológico-político, haja vista que esses exorcistas almejam retomar um modelo de igreja que se alinha mais ao perfil tridentino do que pós-conciliar. Esse conservadorismo, nesse caso, é entendido como uma aproximação maior ao modelo tridentino, sem, contudo, negar completamente certos elementos de abertura social elaborados no Concílio Vaticano II, principalmente em relação ao laicato. Para esse texto, escolhemos como objeto de análise o discurso narrativo ${ }^{2}$ presente nos livros de três exorcistas italianos: Gabriele Amorth (1925-2016), Raul Salvucci (1926-2012) e Candido Amantini (1914-1992), representantes importantes desse projeto de revival do exorcismo na Itália.

Esse projeto teológico-político não foi somente uma resposta dada pelos exorcistas às mudanças no catolicismo pós-conciliar e na sociedade italiana após a Guerra Fria. Uma parte do clero, embora não defendesse a volta do exorcismo diretamente, também se posicionou em defesa de um modelo tridentino ao invés de acatar com positividade as mudanças propostas pelo Concílio Vaticano II e seus desdobramentos, que deram pouca ou nenhuma atenção ao exorcismo (Young 2016:209). Uma parte do clero e da Santa Sé não aceitou essa "modernização do catolicismo"3 que, apesar de não ser completa, foi possível em vários aspectos, tais como: a maior aceitação da pluralidade interna e externa ao catolicismo; incorporação dos laicos e descentralização pastoral da Igreja; fé menos institucional e mais individual e autônoma; enfoque social da instituição no cumprimento do seu projeto pastoral. Marzano e Ubinati caracterizam esse grupo de resistência como "tradicionalistas anticonciliares", os quais têm dificuldade em dialogar com a sociedade hodierna, com a missa na língua vernácula, com o Vaticano II e com a pentecostalização da Igreja por meio dos movimentos carismáticos (Marzano \& Ubinati 2013:587).

Contudo, em relação a essa última afirmação de Marzano e Ubinati, temos algumas problematizações a serem feitas. Nesse sentido, podemos afirmar que esses sacerdotes, que não acataram as diretrizes do Vaticano II e seus desdobramentos modernizantes, estão alinhados a um perfil tridentino de igreja. A grande maioria dos exorcistas italianos encontra-se nessa vertente tradicionalista, até porque objetivam retomar uma prática deixada de lado pela Santa Sé desde meados do século XIX (Pires 2014) e desconsiderada no próprio Concílio Vaticano II. Esse tradicionalismo não se estende a todas as áreas e torna-se complexo e contraditório: os exorcistas, por exemplo, dificilmente condenam os movimentos carismáticos. Pelo contrário, foram os seus incentivadores e reforçadores da presença laica no rito do exorcismo e nos grupos de oração de libertação. Os padres dirigentes da Associação Internacional dos Exorcistas ${ }^{4}$ são os que mais querem conservar o perfil tridentino da Igreja e controlar e regular a prática do exorcismo na Itália e no mundo. Já os outros seguem parcialmente esse modelo, contando com mais espaços de flexibilidade e autonomia no modo de proceder com o ritual. Esse movimento de renovação da Igreja Católica a partir do Vaticano II gerou uma contracorrente discordante, demonstrando como a chamada ortodoxia é dividida, conflitante e plural. 
Neste artigo, analisaremos, com base na produção literária de exorcistas italianos, de que forma essa articulação narrativa foi capaz de empreender um projeto teológico-político de retomada do exorcismo, criando uma discursividade combativa à pluralidade religiosa na Itália a partir dos anos 1980, com especial atenção à condenação dos novos movimentos religiosos (NMR). Iniciaremos a nossa argumentação apresentando alguns exorcistas e as suas relações com esse projeto teológico-político para, posteriormente, identificarmos as tensões e disputas entre essas narrativas diabolizantes com algumas expressões dos NMR. Entendemos as linguagens diabolizantes criadas por meio da produção literária dos exorcistas como estratégias de reafirmação de um modelo de igreja e de sociedade que está para além do âmbito teológico e religioso, estabelecendo-se como estratégias políticas que respondem também à pluralização cultural da sociedade italiana.

\section{Para além da expulsão do mal: o projeto teológico-político e suas narrativas}

Afinal, quem são os exorcistas italianos que, a partir dos anos 1980, iniciaram um projeto sistemático de viés teológico-político de retomada do exorcismo? A resposta é complexa e atém-se à análise de parte da literatura produzida por alguns dos principais representantes do grupo a nível nacional, com especial atenção àqueles que atuaram em Roma ou mantiveram contato com a Associação Internacional dos Exorcistas (AIE). Apesar desses sacerdotes atuarem especificamente na Itália, suas obras adquiriram um caráter internacional devido à circularidade e à inovação desse projeto narrativo.

Corrado Balducci nasceu em 1923, em Monte Castello, e assumiu funções importantes na Cúria Romana. Ficou conhecido por sua atuação na diocese de Roma como demonólogo e, ocasionalmente, como exorcista. Em seu livro Il diavolo, publicado em 1988 e revisado na edição de 1990, Corrado Balducci parece mais preocupado em defender a existência do diabo a nível institucional do que fazer um projeto de retomada social do exorcismo e da possessão, algo que está mais claro nas obras A possessão diabólica (1974) e Adoratori del diavolo e rock satanico (1991). O seu projeto de "fazer crer" narrativo endereçava-se, sobretudo, à própria Igreja Católica e sua hierarquia.

Já Gabriele Amorth nasceu em Modena em 1925, vindo a falecer em Roma em 2016, sendo o seu último livro publicado em 2013. Foi ordenado presbítero em 1954 e ingressou na ordem de São Paulo, tornando-se um especialista em mariologia. Em 1986, iniciou, por mandado do cardeal vicário Ugo Poletti, seu percurso como exorcista na diocese de Roma. Foi formado pelo mais reconhecido exorcista da Scala Santa, Candido Amantini (1914-1992) (Amorth 2014:19, 22). Amorth deu continuidade a essa tradição exorcística romana, tornando-se um dos exorcistas mais conhecidos na Itália e no mundo. É com o sacerdote de Modena que a volta do exorcismo adquire amplitude institucional, social e midiática, consolidando-se como projeto teológico-político compartilhado por vários de seus colegas de ofício, 
principalmente no território italiano com a Associação Internacional dos Exorcistas, mas não restrita a ela. Amorth publicou vários livros sobre o tema do exorcismo e da possessão, sendo muitos deles traduzidos em outras línguas (português, francês, espanhol, inglês, dentre outras).

Raul Salvucci nasceu em Corridonia, na região das Marche, em 1926. Foi ordenado sacerdote em 1950 e atuou como exorcista em Fermo, porém sempre em contato com Roma em decorrência das reuniões da Associação Internacional dos Exorcistas, da qual foi um dos fundadores. Em 1975, assumiu o cargo de exorcista em Fermo, sendo também o fundador do grupo carismático Anno Domini di Fermo, vindo a falecer em 2012. Salvucci seguiu os passos de Gabriele Amorth, um amigo e colega de profissão, ao adotar uma forma de narrar muito semelhante, citando-o várias vezes em seu livro como referência para a prática de libertação do mal. Ele publicou apenas dois livros sobre o tema. O primeiro, lançado em 1992 com o título Indicazioni pastorali di un esorcista, acabou adotando nas edições futuras o nome de Cosa fare con questi diavoli? Indicazioni pastorali di un esorcista (Salvucci 2016). O segundo, chamado Le potenze malefiche (Salvucci 2008), teve a sua primeira edição em 1998. Seus livros seguiram um caráter de divulgação, sendo redigidos por meio de perguntas e respostas, em uma linguagem acessível ao grande público.

O recorte temporal das publicações atém-se, sobretudo, ao período da nossa investigação, entre 1980 e 2013. Gabriele Amorth foi o que mais publicou livros sobre o tema, obtendo maior repercussão nacional e internacional. Ele foi, sem dúvidas, o elemento central na retomada do exorcismo como prática e como temática dentro e fora da Igreja Católica. As narrativas de Amorth tornaram-se modelos dessa literatura exorcística italiana e mesmo mundial. Mas, antes dele, Corrado Balducci já havia iniciado um trabalho similar, porém muito mais próximo ao campo da demonologia do que do relato de testemunhos e da prática direta como exorcista. Elegendo as obras desses três exorcistas (Balducci, Amorth e Salvucci), pudemos entender o percurso narrativo que se iniciou antes, durante e depois da primeira publicação de Amorth em 1990, intitulada Un esorcista racconta (Amorth 2014). No presente artigo, essas obras não serão analisadas em profundidade, haja vista que o objetivo principal é entender a relação entre o projeto de retomada do exorcismo e as minorias religiosas na Itália, as quais representam uma parte do pluralismo cultural da nação.

É interessante levar em consideração o período de formação religiosa e cultural desses padres, que ocorreu inicialmente na conjuntura pré-Concílio Vaticano II, passando, posteriormente, pelo período de formulação e de recepção do referido evento. Nesse sentido, a volta do exorcismo como projeto teológico-político está atrelada não somente ao ofício exercido por tais sacerdotes, mas a uma visão de igreja tridentina que havia se perdido e que precisava ser recuperada em alguns de seus elementos silenciados no Vaticano II. Apesar desse projeto teológico-político manter uma postura de resistência e desconfiança de alguns preceitos conciliares, ele não os nega completamente, na medida em que se constitui também como um projeto pas- 
toral. Esse caráter "pastoral" é a chave de leitura do concílio, defendida nos discursos de inauguração e ao longo das documentações originadas do Vaticano II (Almeida, Manzini e Maçaneiro 2013; Costa 2007). No entanto, os modos de conduzir essa "pastoral", para os exorcistas, são diferentes daquele proposto no concílio de 1962. Segundo Corrado Balducci,

Infelizmente nas últimas décadas tivemos também que assistir a uma negação desse tipo, uma antecipação de uma vasta crise doutrinal que se está alastrando entre o clero. No período pós-conciliar foi se formando uma corrente teológica, que apesar de estar em contraste com o ensinamento bíblico, com o Magistério Eclesiástico e com o senso comum que vai afirmando e propagando a morte de satanás. [...] E eis o livro sobre o diabo. Esse tem, principalmente, uma dupla finalidade: reafirmar a existência; ver então como podemos reconhecê-lo presente na sua atividade maléfica (Balducci 1994:11, tradução nossa) ${ }^{5}$.

É, assim, tanto um projeto pastoral de auxílio aos "assolados pelo mal" quanto um plano teológico-político de defesa de alguns elementos tridentinos marginalizados ou abolidos no Concílio Vaticano II e na conjuntura social italiana de fins da Guerra Fria. Nenhum exorcista, é claro, opôs-se diretamente ao conteúdo do referido concílio, haja vista o conflito direto que isso poderia causar com a hierarquia eclesiástica. As críticas são sutis e indiretas, formuladas de forma comedida. No discurso de Raul Salvucci, por exemplo, está presente tanto a dificuldade em aceitar a laicização da sociedade quanto em aceitar plenamente o conteúdo mais "modernizante" proposto no Vaticano II que, de certa forma, deixou de lado o ofício exorcístico e os "perigos" dos grupos ocultistas:

Até os dias do Concílio Vaticano II, quando se realizava ainda a Missa em latim, os sacerdotes ao final da Missa faziam uma oração a são Miguel: "Lance no inferno satanás e seus espíritos malignos que vagam pelo mundo". Em seguida essa oração foi abolida bem no momento errado, exatamente enquanto começava a expansão da presença de satanás na nossa sociedade. Essa é a presença ordinária (Salvucci 2008:47, tradução nossa) $)^{6}$.

Essa sociedade, que imerge na realidade materialista, procura compensação das necessidades espirituais nas mais variadas formas de contato com o oculto. [...] Se a Igreja quisesse, por meio dos ensinamentos das religiões, poderia ter uma documentação válida sobre a orientação da nova geração em relação a essas experiências: mas, provavelmente, é mais cômodo ignorar essas coisas (Salvucci 2008:67, tradução nossa) ${ }^{7}$. 
A retomada do exorcismo não foi elaborada apenas com o objetivo de recuperar um ritual em decadência desde o século XIX. Junto à recuperação do ritual como elemento importante na luta entre "bem e mal", "dor e libertação", entre "Deus e o diabo", estava presente um projeto pastoral que almejava trazer de volta os católicos e os incrédulos para a vida religiosa institucional. Em meio a uma sociedade plural, relativizante e circundada por uma religião de tradição (cultural), fez-se necessário, por parte dos exorcistas, reforçar o papel da Igreja no mundo a partir de sua autoridade e de sua identidade mais próxima ao modelo tridentino. $\mathrm{O}$ exorcismo foi um instrumento que concatenou esses fatores débeis da vida católica na Itália, permitindo uma possível reintegração eclesial. O percurso de "libertação" normalmente exige do exorcizando uma postura de reintegração religiosa, ou seja, de retorno à vida eclesial e ritualística (frequentar a missa, eucaristia, confissão).

As obras produzidas por Balducci, Amorth e Salvucci inserem-se em uma modalidade narrativa que acabou se formando ao longo da década de 1980, mas mantêm certas especificidades na leitura que fazem dos fenômenos "mágicos", culturais e eclesiásticos. Balducci foi, sem dúvida, o que mais se destoou desse perfil discursivo exorcístico, pois seus livros aproximam-se mais de um tratado demonológico contemporâneo (Clark 2006) do que da narratividade presente em Amorth e Salvucci. No entanto, ele foi um dos primeiros a iniciar de forma sistemática a publicação de textos sobre o mundo "diabólico" e da possessão na Itália do pós-guerra.

Até chegarmos ao ponto de consolidação do projeto teológico-político com os opúsculos de Amorth, um caminho anterior foi traçado, abrindo espaço no discurso social, nos meios de comunicação e dentro da própria instituição. Apesar das diferenças entre os três exorcistas, suas obras normalmente são citadas entre eles e, quando se trata de Balducci, algumas críticas são tecidas à sua falta de experiência como exorcista e às suas ideias sobre os fenômenos paranormais. Para o presente artigo, o enfoque recai sobre a relação entre esse projeto teológico-político e os novos movimentos religiosos na Itália, os quais representam, em parte, o cenário do pluralismo religioso nesse país.

\section{Pluralidade religiosa e resistência católica: o olhar dos exorcistas italianos}

A geografia religiosa da Itália passou por uma mudança significativa nas últimas décadas, deixando de ser quase que exclusivamente católica para abrir-se à pluralidade religiosa e cultural (Pace 2011a, 2011b, 2014). A volta do exorcismo na Igreja Católica na Itália coincide com essa ampliação das religiões "estrangeiras" que, de acordo com a nossa hipótese, está envolvida nessa trama histórica que propiciou esse revival. Certamente essa ligação não ocorreu de maneira causal e direta, mas por meio de uma complexa rede discursiva e narrativa que circulava naquele momento.

Os exorcistas costumam ver com desconfiança o avançar da pluralidade religiosa, pois veem nela uma perda do referencial católico que até então ordenava a 
sociedade italiana com mais hegemonia. Essa leitura político-eclesial contém traços marcados de uma visão de igreja tridentina que resulta na dificuldade em aceitar o ecumenismo e o diálogo com outras crenças, ambas noções propostas no Concílio Vaticano II (Almeida, Manzini e Maçaneiro 2013; Costa 2007). Essa questão intensifica-se quando o outro credo incorpora aspectos mágicos, holísticos ou qualquer outra referência ao mundo do oculto, normalmente interpretado pela Igreja como diabólico. Como afirma o exorcista Gabriele Amorth, a partir de uma discursividade ligada a uma ideia tridentina do mundo e da Igreja,

Em primeiro lugar, analisemos a situação do mundo consumista do ocidente, em que o sentido materialista e hedonista da vida fez com que muita gente perdesse a fé. Penso que, sobretudo em Itália, uma grande parte da culpa cabe ao comunismo e ao socialismo que, com as doutrinas marxistas, dominaram nestes últimos anos a cultura, a educação e o mundo do espetáculo. Em Roma, por exemplo calcula-se que só 12\% dos habitantes vão à Missa ao domingo. É matemático: onde a religião se cala, cresce a superstição. Daí a difusão, especialmente entre os jovens, da prática do espiritismo. Da magia e do ocultismo. E ainda o yoga, o zen e a meditação transcendental: tudo práticas fundamentadas na reencarnação, na dissolução da pessoa humana na divindade ou, pelo menos, em doutrinas inaceitáveis para um cristão (Amorth 2014:60).

Ainda que exista essa pluralização da geografia religiosa da Itália contemporânea, não podemos afirmar, pelo menos quantitativamente, que se trata de um fenômeno hegemônico. $\mathrm{O}$ índice de italianos que mudam de religião é baixíssimo, sendo relativamente maior quando abordamos a questão do ateísmo entre os mais jovens (Garelli 2016). No entanto, segundo Pace, "a Itália está se tornando uma sociedade caracterizada por uma diversidade religiosa muito articulada e, portanto, totalmente inédita" (Pace 2011a:7) ${ }^{8}$. Em uma análise comparativa, considerando a história da Itália após as Grandes Guerras, podemos afirmar que nas últimas três décadas o campo religioso passou por uma mudança significativa a nível nacional e europeu em decorrência, sobretudo, do aumento do fluxo migratório advindo da África, Ásia, América Latina e Leste Europeu. Mas se pensarmos de forma quantitativa, temos ainda uma maioria católica de italianos que não permanece abaixo dos $80 \%$, até porque mais da metade dos imigrantes residentes na Itália pertencem ao cristianismo (seja católico, seja ortodoxo), como podemos verificar no gráfico abaixo:

Entre os residentes na Itália, com a cota de 60.665.551 unidades (sendo 55.639.398 cidadãos), segundo o balanço demográfico de 2016 realizado pelo Instituto Nacional de Estatística, dos quais 5.026 .153 são estrangeiros (8,3\%), apenas 3,2\% pertencem a minorias religiosas: 1.781 .807 unidades, se considerarmos os cidadãos italianos, e 5.672.807 unidades, se inserirmos os imigrantes não cidadãos (Introvigne 
\& Zoccatelli 2017). Desses 3,2\%, somente uma parcela reduzida pertence aos novos movimentos religiosos. A maioria, como identificamos no gráfico anterior, é de cristãos (católicos, ortodoxos e protestantes) e muçulmanos.

\section{FIGURA 1. CITTADINI STRANIERI (6 ANNI E PIÙ) PER APPARTENENZA RELIGIOSA. Anno 2011-2012, Composizione percentuale.}

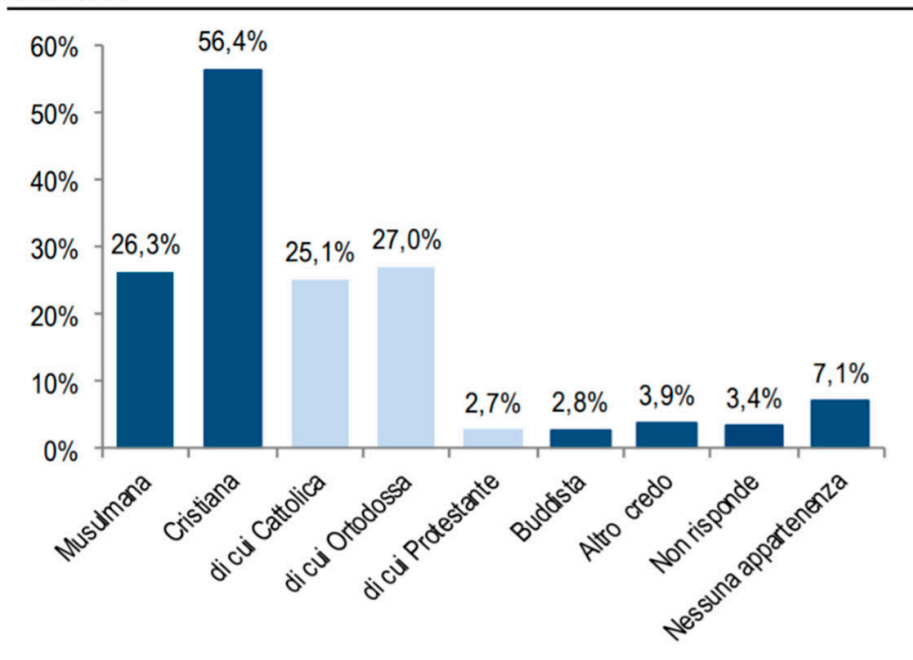

Tabela 1: Pertencimento religioso dos imigrantes - Dossier Statistico Immigrazione 2016

\begin{tabular}{|l|l|l|}
\hline Ortodoxos & 1.541 .000 & $30,7 \%$ \\
\hline Católicos & 908.000 & $18,1 \%$ \\
\hline Protestantes e outros cristãos & 255.000 & $5,0 \%$ \\
\hline Muçulmanos & 1.609 .000 & $32,0 \%$ \\
\hline Judeus & 7.000 & $0,1 \%$ \\
\hline Hinduístas & 149.000 & $3,0 \%$ \\
\hline Budistas & 111.000 & $2,2 \%$ \\
\hline Outras religiões orientais & 78.000 & $1,6 \%$ \\
\hline Ateus e agnósticos & 227.004 & $4,5 \%$ \\
\hline Religiões tradicionais & 56.000 & $1,1 \%$ \\
\hline Outros & 85.000 & $1,7 \%$ \\
\hline Total & $\mathbf{5 . 0 2 6 . 0 0 4}$ & $\mathbf{1 0 0 , 0 \%}$ \\
\hline
\end{tabular}

Fonte: Introvigne \& Zoccatelli (2017). 
Além das vertentes cristãs e dos muçulmanos, das religiões com maior tradição histórica destacam-se os budistas (com 2,2\%) e os hinduístas (3,0\%). Contudo, tratase ainda de uma porcentagem muito baixa se levarmos em consideração a totalidade de imigrantes ou mesmo a população italiana. Os grupos pertencentes aos chamados novos movimentos religiosos são pouco expressivos também entre os cittadini.

A seguir, uma tabela mais detalhada acerca das minorias religiosas entre os cidadãos italianos:

Tabela 2: Estimativa (CESNUR 2016) das minorias religiosas entre os cidadãos italianos

\begin{tabular}{|l|c|c|}
\hline Judeus & 36.256 & $2,0 \%$ \\
\hline Católicos dissidentes ou de "franja" & 25.500 & $1,4 \%$ \\
\hline Ortodoxos & 212.318 & $11,9 \%$ \\
\hline Protestantes & 450.392 & $25,3 \%$ \\
\hline Testemunhas de Jeová (e similares) & 424.259 & $23,8 \%$ \\
\hline Mórmons (e similares) & 26.750 & $1,5 \%$ \\
\hline Outros grupos de origem cristã & 6.000 & $0,3 \%$ \\
\hline Muçulmanos & 302.090 & $17,0 \%$ \\
\hline Bahá'í e outros grupos de matriz islâmica & 4.250 & $0,3 \%$ \\
\hline Hinduístas e neo-hinduístas & 35.672 & $2,0 \%$ \\
\hline Budistas & 157.011 & $8,8 \%$ \\
\hline Grupos Osho e derivados & 4.100 & $0,3 \%$ \\
\hline Sikh, radhasoami e derivações & 14.693 & $0,8 \%$ \\
\hline Outros grupos de origem oriental & 3.530 & $0,2 \%$ \\
\hline Novas religiões japonesas & 3.150 & $0,2 \%$ \\
\hline Área esotérica e da "antiga sabedoria" & 16.450 & $0,9 \%$ \\
\hline Movimentos do potencial humano & 30.000 & $1,7 \%$ \\
\hline Movimentos organizados, New Age e Next Age & 20.000 & $1,1 \%$ \\
\hline Outros & 9.386 & $0,5 \%$ \\
\hline Total & $\mathbf{1 . 7 8 1 . 8 0 7}$ & $\mathbf{1 0 0 , 0} \%$ \\
\hline
\end{tabular}

Fonte: Introvigne \& Zoccatelli (2017).

Diante dessa conjuntura, podemos afirmar que o discurso católico defendido por grande parte dos exorcistas, que ressalta os perigos da pluralidade religiosa e dos novos movimentos religiosos, se alimenta mais de um posicionamento retórico-político de não aceitação da diversidade religiosa do que propriamente de um dado verificável socialmente. Essa demonização das "religiões do outro" não é algo novo 
no discurso eclesiástico, porém se instaura de maneira peculiar no contexto analisado em nossa pesquisa, aliando-se a linguagens políticas e teológicas específicas.

De acordo com parte do clero (incluso os exorcistas) afiliado ao pensamento tridentino, essa conjuntura pluralística prejudicaria a "identidade católica" e, consequentemente, a nacional, além de abrir espaço para "superstições", práticas diabólicas ou crenças que se opõem ao catolicismo (espiritismo, New Age, satanismo, leitura de cartas, adivinhadores, religiões de matriz africana). Ortodoxos, muçulmanos e protestantes não aparecem como alvos recorrentes nos debates veiculados por exorcistas italianos, seja por uma questão política, seja por não os considerarem como uma ameaça à fé católica. Padre Candido Amantini e seu discípulo Gabriele Amorth deixam claro em suas declarações tal posicionamento, mesclando-as com críticas morais ligadas a um discurso de direita:

A experiência o ensinou a aceitar como reais os fenômenos não justificáveis racionalmente. E a descobrir que, normalmente, os distúrbios psíquicos se somam aos efeitos de presenças maléficas. Padre Candido - lembra - para chegar à diagnose às vezes procurava um psiquiatra. Muitos fatores - insiste - encorajam o maligno: "A fé que tremula, o materialismo, o consumismo, o difundir-se, especialmente entre os jovens, das práticas espíritas, magia, ocultismo" (La Stampa 1992:16, grifo nosso, tradução nossa) $)^{9}$.

A pluralidade religiosa na Itália advém, sobretudo, dos fluxos migratórios, principalmente se considerarmos os grandes agrupamentos tradicionais (islamismo, ortodoxos, protestantes). No entanto, quando avaliamos os outros grupos e os novos movimentos religiosos, notamos que a porcentagem dos participantes é muito baixa tanto entre os imigrantes quanto entre os cidadãos italianos. Esse alerta do "perigo das seitas" na Itália das últimas décadas, veiculado pelos exorcistas em suas narrativas orais e textuais (Amorth 2014; Salvucci 2016), trata-se, desse modo, de um instrumento discursivo que fundamentou a retomada da atuação da Igreja no campo espiritual e de combate ao "mal". Uma outra leitura possível seria a de um medo da competição no mercado religioso e de uma maior perda do espaço católico na sociedade causado pela pequena - porém significativa, diante do histórico de pluralização religiosa na Itália (Garelli 2006) - ampliação dos novos movimentos religiosos e de religiões trazidas pelos imigrantes.

Como podemos verificar no discurso de Gabriele Amorth, a crítica dos exorcistas não se desvincula de uma trama social e política maior na qual a Itália estava e ainda está inserida. A narrativa organizada pelos exorcistas mantém, como afirmamos ao longo do texto, um caráter teológico-político não somente por estar atrelada a um projeto de retomada nacional e internacional do exorcismo, mas também por fazer parte de uma rede de linguagens políticas circulantes em diferentes modalida- 
des discursivas e institucionais, como as classificadas por Enzo Pace na categoria de "direita etnonacionalista":

Nas retóricas políticas das direitas etnonacionalistas europeias, que tendem a estigmatizar o islã como único verdadeiro inimigo da civilização europeia, o chamado à defesa da identidade cristã soa ambíguo: o cristianismo do qual se fala é, na realidade, a cifra simbólica que revela a pulsão ideológica à limpeza étnica de uma Europa que parece aos olhos deles decadente, contaminada de religiões bárbaras, estranhas e perigosas. É o sinal da dificuldade crescente por parte de uma quota consistente de europeus em aceitar o inédito pluralismo religioso que vai se difundindo nas nossas sociedades do Velho Continente (Pace 2011a:36, tradução nossa) ${ }^{10}$.

A existência de uma parcela do clero que ainda defende uma perspectiva tridentina de igreja não eliminou os outros projetos eclesiais com mais afinidade com as formulações do Concílio Vaticano II. Ao mesmo tempo que a Igreja Católica tenta manter a sua presença cultural na sociedade italiana, defendendo o ensino religioso nas escolas públicas ou por meio dos discursos da Conferência Episcopal Italiana e do papa sobre a vida civil em geral, ela foi capaz de criar diversos centros pastorais de acolhimento e reintegração para os imigrantes. Tais centros estão presentes em toda a Itália, com maior concentração na região do Lácio e ao Norte (Pace 2014:110).

Nesse sentido, o projeto teológico-político dos exorcistas dialoga com uma parcela do clero de viés tridentino, porém não representa o posicionamento da Igreja Católica em geral. Não sabemos como essa vertente tradicionalista se organiza em termos quantitativos dentro da Santa Sé e nas paróquias italianas. Entretanto, essa linguagem teológico-política em afinidade com o que Enzo Pace considera como uma destra etno-nazionalista acabou repercutindo e ganhando dimensões consideráveis dentro e fora do mundo católico.

A intolerância religiosa dos exorcistas italianos apresenta-se de forma mais evidente e declaradamente conflituosa quando o alvo são os novos movimentos religiosos ou práticas consideradas por eles como "diabólicas" e causadoras de possíveis obsessões e "possessões demoníacas". Segundo eles, a volta do exorcismo coincide com o retorno da magia e do fortalecimento das estratégias "diabólicas" presentes nas diversas "seitas" espalhadas pela sociedade italiana.

\section{Os novos movimentos religiosos segundo os exorcistas italianos: incompatibilida- des e tensões com a crença católica}

Os chamados novos movimentos religiosos (NMR) possuem três grandes questões desafiadoras para os estudiosos da história das religiões. A primeira é a dificuldade de encontrar uma classificação precisa para cada agrupamento, visto que eles 
se apropriam e ressignificam os conteúdos de novas e antigas tradições espirituais, mágicas, esotéricas e ocultistas. A segunda questão é de ordem conceitual, haja vista que tais grupos propõem uma forma de experienciar a crença de um modo peculiar e diferente dos monoteísmos e das antigas tradições religiosas. A última seria em relação à forma de pertencimento dos seguidores dos referidos agrupamentos. Os NMR, com particular atenção à New Age, organizam-se a partir de uma network (presencial ou on-line) (Amaral 2000:29) de saberes e crenças, fugindo dos padrões doutrinais organizados que estamos habituados a conhecer por meio dos monoteísmos, sobretudo cristãos. Normalmente, não existe um órgão regulador, uma igreja unificante, uma doutrina estabelecida a ser seguida. A religiosidade desenvolve-se a partir de uma rede complexa e interligada de apropriações, de saberes, de práticas, de ritos e símbolos. Seus seguidores são, na maioria das vezes, nômades espirituais ${ }^{11}$, podendo transitar em diferentes conteúdos e comunidades.

Diante dessa complexidade, optamos por abordar brevemente alguns grupos presentes na Itália contemporânea pertencentes aos novos movimentos religiosos e que foram alvo de críticas por parte das publicações e discursos dos carismáticos católicos e, consequentemente, dos exorcistas. A antropóloga italiana Gatto Trocchi divide os NMR em quatro grandes vertentes que, ao final, acabam dialogando entre si em muitos de seus aspectos e formas de estruturação: 1) os movimentos dissidentes do cristianismo, como as Testemunhas de Jeová e a igreja de Moon; 2) os de origem oriental, inspirados no hinduísmo, budismo, tantrismo e nas religiões japonesas; 3) as comunidades psicoespirituais que se destinam à criação de terapias holísticas e práticas taumatúrgicas, bem como ao desenvolvimento do potencial mental e físico dos indivíduos; 4) e, por último, os agrupamentos de caráter esotérico e mágico-ocultista, neopaganismos e os considerados (às vezes somente pelo discurso eclesiástico) como satanismo contemporâneo. Dentre esses grupos, espalhados por todo o território italiano e em todas as faixas sociais (Gatto Trocchi 1998:12), os mais reconhecidos como perigosos pelos exorcistas tornaram-se aqueles das vertentes New Age e satanista. Para o presente texto, nos ateremos, principalmente, a esse primeiro agrupamento, os new ages.

Nem mesmo o clero e os exorcistas conseguem fornecer uma definição clara para aquilo que estão criticando. Em seus discursos, na maior parte das vezes, os NMR aparecem como contrários à fé cristã ou como práticas diabólicas causadoras da possessão. Ainda que critiquem, particularmente, as comunidades identificadas como New Age, eles acabam inserindo como alvo de uma "guerra espiritual" qualquer tipologia pertencente ao que entendem por novos movimentos religiosos. Dentre os grupos criticados, podemos citar os contidos na seguinte tabela, que nos mostra uma pesquisa quantitativa de 2012 e 2018 sobre alguns dos NMR presentes na Itália. Como já mencionado anteriormente, trata-se de números pouco expressivos diante da grande maioria católica e de imigrantes muçulmanos e ortodoxos, porém com um pequeno aumento numérico de participantes entre 2012 e 2018. 
Tabela 3: Área esotérica e da "antiga sabedoria" - Estimativa CESNUR de 2012 e 2018

\begin{tabular}{|l|c|c|c|c|}
\hline & \multicolumn{2}{|c|}{2012} & \multicolumn{2}{c|}{2018} \\
\hline $\begin{array}{l}\text { Neopagãos, neoxamanismo, } \\
\text { Wicca }\end{array}$ & 3.000 & $20,0 \%$ & 3.200 & $19,4 \%$ \\
\hline Rosacruz & 2.000 & $13,3 \%$ & 2.100 & $12,7 \%$ \\
\hline $\begin{array}{l}\text { Martinistas, kremmerzianos, } \\
\text { magia cerimonial }\end{array}$ & 900 & $6,0 \%$ & 2.000 & $12,1 \%$ \\
\hline Neotemplários & 800 & $5,3 \%$ & 850 & $5,1 \%$ \\
\hline Grupos teosóficos e derivados & 3.000 & $20,0 \%$ & 2.850 & $17,3 \%$ \\
\hline Fraternidades universais & 700 & $4,7 \%$ & 700 & $4,2 \%$ \\
\hline Espiritismo organizado & 1.000 & $6,7 \%$ & 1.000 & $6,1 \%$ \\
\hline Movimentos de discos voadores & 1.000 & $6,7 \%$ & 1.000 & $6,1 \%$ \\
\hline Igrejas e movimentos gnósticos & 1.500 & $10,0 \%$ & 1.500 & $9,1 \%$ \\
\hline Satanismo organizado & 300 & $2,0 \%$ & 350 & $2,1 \%$ \\
\hline Outros & 800 & $5,3 \%$ & 950 & $5,8 \%$ \\
\hline Total & 15.000 & $100,0 \%$ & 16.500 & $100,0 \%$ \\
\hline
\end{tabular}

Fonte: Introvigne \& Zoccatelli (2018a).

Os novos movimentos religiosos apresentam vários elementos sincréticos, incorporando tradições esotéricas antigas e saberes contemporâneos ressignificados: neoplatonismo, gnosticismo, hermetismo, qabbalah, alquimia, astrologia e mitologias variadas. Possuem também pontos de referência no ocultismo do século XIX e XX, de Eliphas Lévi a Madame Blavatsky, de Gurdjieff a Aleister Crowley, de Rudolph Steiner a Giuliano Kremmerz, bem como elementos mágicos e rituais advindos das religiões orientais (Gatto Trocchi 1996:10).

Os NMR estão menos preocupados em organizar uma doutrina fixa e única, sendo o mais importante, em grande parte dos casos, a difusão dos saberes sem adesões rígidas. Há uma busca pela fluidez da espiritualidade, pela preocupação holística com o indivíduo e com a coletividade, sobretudo nas comunidades New Age (Filoramo 1999). Não é por acaso que misturam política e ecologia com práticas rituais mágicas, filosofias orientais e terapias que envolvem "energias" do corpo e da mente. Entretanto, alguns grupos são mais severos em seus rituais iniciáticos e na adesão dos participantes, como os satanistas, Testemunhas de Jeová e Igreja da Unificação (Moon).

Tratando-se do movimento New Age, podemos afirmar que ele dialoga com o Transcendentalismo, o Espiritualismo, Teosofia, New Thought e Christian Science (Berzano 2010:76), elencando noções escatológicas advindas de uma busca por uma 
"nova era" não apenas social, mas subjetiva ${ }^{12}$. Segundo Leila Amaral, foram os Estados Unidos o local de surgimento do movimento Nova Era, mais especificamente em São Francisco, por meio do Esalem Institute (Big Sur e San Francisco), o centro mais conhecido do Human Potential Movement já na década de 1950. O movimento foi "uma convergência da comunidade metafísica do oculto com a cultura da droga e experiências místicas e psíquicas, bem como a interação da psicologia humanista, introduzida por Maslow, com a Gestalt Therapy, da qual Fritz Perls foi um dos principais difusores [...]" (Amaral 2000:23). O fenômeno começou a tornar-se visível na década de 1960 e no início da década de 1970 (Berzano 2010:138-143).

Os new ages podem ser definidos como sistemas religiosos que fogem dos aspectos tradicionais de uma religião monoteísta e abarcam uma visão global e transformadora. "Destacava-se, desde os anos 1960 e 1970, apesar da idealização das 'comunidades' e 'grupos de luz', a forma organizacional característica e hegemônica do movimento Nova Era, no momento atual, o network" (Amaral 2000:29). Os locais de encontro são, geralmente, reuniões anuais, workshops, conferências e festivais (nacionais e internacionais). Existe um processo contínuo de sacralização do self, uma busca por "liberar o self", o verdadeiro "eu" (self religiosity) (Amaral 2000:31). Os seguidores buscam, ao mesmo tempo, suprir suas necessidades "espirituais" (fortalecimento interior, afirmações positivas do verdadeiro "eu”) e materiais (saúde, prosperidade). A New Age organiza-se a partir da pluralidade, sincretismo e plasticidade, com a existência de uma ligação estreita entre Nova Era e grupos holísticos (Filoramo 1999:32-33), sendo este o principal caminho de definição do referido movimento.

A concepção mágica da Nova Era trabalha com o poder dado a alguns homens por Deus ou deuses (ou mesmo demônios), podendo ser direcionado para fazer o bem ou o mal a alguém. Temáticas como as das energias (positivas e negativas), força do pensamento, Feng Shui, magia soft (branca) e magia hard (negra) transitam entre as reuniões dos participantes da New Age, de acordo com o trabalho de campo realizado pela antropóloga Leila Amaral (2000:42-43). Nota-se, portanto, as apropriações do xamanismo norte-americano, da angelologia, cromoterapia e terapia de cristais, astrologia e plantas medicinais (Amaral 2000:47).

Em fins dos anos 1960, acreditava-se - principalmente entre alguns grupos new age, movimento hippie e outros agrupamentos do mesmo perfil - que estava por se iniciar uma Nova Era, representada pela saída da Era de Peixes para a de Aquário. O conceito de new age conectou-se aos movimentos de contestação da ordem consumista vigente nas décadas de 1960 e 1970, quando a Guerra Fria já havia elegido o seu vencedor (o capitalismo), embora o marco continue a ser a queda do muro em Berlim. Diante dessa "ordem imposta", surgiram movimentos de revolta não somente nas universidades (temos o maio de 1968, por exemplo), mas rebeliões que se pautavam em outras crenças religiosas e éticas, de busca de uma coletividade e de uma subjetividade holística. Temas como ecologia e conexão com a natureza, vida comunitária, astrologia, energias do mundo, passaram a circular nos chamados grupos new 
age. Nomenclatura essa não necessariamente usada pelos seus praticantes. $\mathrm{O}$ uso do referido termo ficou mais claro a partir dos anos 1980, com a divulgação do livro The Aquarian Conspiracy, de Marilyn Ferguson (Berzano 2010:163).

Algumas experiências iniciais foram desenvolvidas na Europa pelas comunidades Findhorn na Escócia e o Damanhur e o Villaggio Verde na Itália (Berzano 2010:177, 375). A partir dos anos 1970, o conteúdo da New Age passou a ser divulgado nos Estados Unidos por várias religiões metafísicas, da Rosacruz à Unity School of Christianity. O Villaggio Verde nasceu por meio de Bernardino Del Boca, escritor e diretor da revista L'Età dell'Acquario, editada por Edoardo Bresci, de Turim. Essa comunidade foi fundada como cooperativa em dezembro de 1981 em Novara, norte da Itália. Já a história do Damanhur se desenvolveu por meio de seu fundador Oberto Airaudi, nascido em Balangero em 1950. Airaudi mesclava pranoterapia, espiritismo, saberes teosóficos, tradições filosóficas e religiosas orientais, pensamento ecológico e astrológico. No campo da psicologia transpessoal, destacou-se o psicanalista Roberto Assagioli, reconhecido como um dos inspiradores e estudiosos da New Age na Itália, sendo formado em Zurique por meio de Freud e Jung (Berzano 2010:751, 812).

Por enfatizar uma espiritualidade sem grandes adesões e valorizadora do indivíduo (self), Berzano (2010:255) afirma que a New Age se conecta harmonicamente com a sociedade moderna ao apreciar alguns elementos do individualismo contemporâneo. A mesma leitura faz a Igreja Católica na Itália, porém com tonalidades mais combativas, sobretudo entre os exorcistas e carismáticos. Institucionalmente, podemos citar três documentos promulgados pela hierarquia eclesiástica na Itália em combate aos novos movimentos religiosos, incluso a New Age e seus derivados: Il fenomeno delle sette o nuovi movimenti religiosi: sfida pastorale, de 1986, proposto pelo Secretariado para o Ecumenismo e Conselho Pontifício para a Cultura; a nota pastoral da Secretaria para o Ecumenismo da CEI, intitulada L'impegno pastorale della Chiesa di fronte ai nuovi movimenti religiosi e alle sette, de 30 de maio de 1993, em Roma; e as Disposizioni Pastorali circa i fenomeni della "superstizione", della "magia" e dei "nuovi movimenti religiosi", assinado em 3 de junho 2001 por Angelo Bagnasco (arcebispo de Pesaro), Francesco Marinelli (arcebispo de Urbino) e Vittorio Tomassetti (bispo de Fano) (Sulpasso 2002:17) ${ }^{13}$.

As críticas feitas pela Igreja Católica na Itália, normalmente veiculadas pelas Conferências Episcopais, não foram numerosas, porém reforçavam o que já estava circulando nas publicações carismáticas e nas obras redigidas por exorcistas locais. $\mathrm{O}$ tom combativo enfatizava a incompatibilidade dos NMR com a fé cristã, tornandose um caminho de afastamento do catolicismo e de aproximação das "forças do mal" (Amorth 2010:45-46; 2013:115).

A resposta cristã à New Age está presente no mistério da Encarnação: o Filho de Deus nasceu da Virgem Maria "para nos salvar". Em nenhum outro nome existe salvação (cf. At 4,12). Ninguém pode se salvar 
sozinho, com técnicas humanas. [...] $\mathrm{O}$ cristianismo não adere a um salvador de invenção humana, mas ao Jesus Cristo do Evangelho, que nos salva por meio da cruz e da ressureição, propõe-nos o caminho das bem-aventuranças e nos faz transcender, embora iluminando e promovendo, o horizonte terreno (Conferenza Episcopale Italiana 1993:208, tradução nossa) $)^{14}$.

Tendo em mente que as bases da doutrina New Age não podem realmente coexistir com a fé cristã, podemos dizer que essa "religiosidade", embasada essencialmente nas potencialidades humanas, convence insidiosamente aqueles que querem fazer parte do círculo dos "poucos", aqueles inquietos sempre à procura de algo novo para abraçar e de alguma coisa pela qual "combater", e o faz colocando-se como mensagem de paz e de harmonia universal (Gasperoni 2000:29, tradução nossa) ${ }^{15}$.

Nas discussões acadêmicas sobre os novos movimentos religiosos, aborda-se também o chamado Next Age, que consistiria em uma hiperindividualização das propostas circulantes nos grupos New Age. Se na New Age o indivíduo é pensado como peça importante nas mudanças globais, na Next Age a mudança social partiria única e exclusivamente do indivíduo e do alcance pessoal de um "estado superior". Prioriza-se a ação sobre si, e não sobre o mundo holisticamente conectado a todos. Como define Introvigne e Zoccatelli (2018b:n.p., tradução nossa), "A sociedade pode também desabar: mas o indivíduo que acessou determinadas técnicas entrará, no entanto, em sua idade de ouro pessoal e privada"16.

O pertencimento dos italianos aos novos movimentos religiosos é ainda pouco expressivo. Se levarmos em consideração a New Age e a Next Age, por exemplo, temos a cifra de 20 mil participantes identificados entre os cidadãos italianos ${ }^{17}$. Os exorcistas e os integrantes do movimento carismático na Itália olham com desconfiança e crítica para essas novas formas de espiritualidade e religiosidade contemporâneas. Os exorcistas assumem tons combativos e relacionam "sob um olhar diabólico" as crenças no Reiki, New Age, Next Age, meditações transcendentais, Tai Chi, tantrismo, cientologia, yoga, zen, maçonaria, Hare Krisna, Sai Baba ${ }^{18}$. As respostas de parte da Igreja Católica em relação a essa pluralidade religiosa - ainda que quantitativamente pequena - não foram sempre harmoniosas. A criação do Grupo de Pesquisa e Informação Sociorreligiosa (GRIS) é emblemática para mostrarmos essa incompatibilidade de crenças e posicionamentos.

A crítica dos exorcistas, pouco atenta às especificidades dos NMR, mesclada a um olhar "diabolizante", foi institucionalmente legitimada pela criação do GRIS, sediado em Bolonha, com aprovação da Conferência Episcopal Italiana (CEI) em 1990. O GRIS consiste em uma associação cultural e religiosa, ligada à Igreja Católica, que se ocupa de investigações sobre religiões, NMR e outras crenças na Itália, principal- 
mente quando existem práticas criminosas e abusivas. $\mathrm{O}$ referido grupo foi um dos criadores, junto com a Associação Internacional de Exorcistas (AIE), do curso anual sobre exorcismo e oração de libertação do Ateneu Pontifício Regina Apostolorum, no qual realizamos um trabalho de campo na sua edição de 2017.

O GRIS funciona como uma espécie de "caça seitas" e de combate à criminalidade ritual desenvolvida por charlatões e criminosos ("feiticeiros", "magos" e outros líderes espirituais) que utilizam as terminologias dos NMR ou mesmo da Igreja Católica para se aproveitarem dos fiéis de diferentes formas (abuso sexual, financeiro, psicológico). Casos desse tipo aparecem com abundância nos jornais utilizados em nossa pesquisa desde os anos 1980 até 2013, assumindo um tom apelativo e polêmico. Alguns dos episódios mais emblemáticos que ilustram com precisão essa situação foi o de Mamma Ebe (Del Boca 1984:8) ${ }^{19}$ e do mago Paolo Oddenino Paris ${ }^{20}$, ocorridos em meados dos anos 1980, envolvendo abusos psicológicos, financeiros e sexuais das vítimas de suas "práticas mágicas".

Ao fazer esse serviço investigativo que, a princípio, mantém uma eficácia social, o GRIS acaba por inserir as crenças não católicas dentro de um mesmo padrão de charlatanismo e criminalidade, conectando-se harmonicamente com a visão defendida por exorcistas e membros da renovação carismática. Essa "narrativa demonizante" constitui-se de várias formas e a partir de vários sujeitos e instituições, inclusive por meio da mídia laica proposta pelo La Repubblica, La Stampa e Corriere della Sera. A retórica eclesiástica veiculada pelos exorcistas parece estar mais ligada a uma justificativa para a volta da prática exorcística e tridentina também associada a uma dificuldade de aceitar a pluralidade religiosa e cultural - do que propriamente a um perigo que os NMR possam causar, haja vista que são ainda numericamente inexpressivos. Esse alerta sobre o "perigo das seitas" é recorrente tanto nos livros quanto nas entrevistas fornecidas aos referidos periódicos pelos exorcistas, como podemos verificar na seguinte fala de Balducci e Amorth ao Corriere della Sera de 1996.

"Não existem sacerdotes preparados no tema dos cultos satânicos", disse Balducci: "Poucos se interessam pela demonologia, pela parapsicologia e pela psiquiatria". E eis a denúncia do padre Amorth, paulino e exorcista da diocese de Roma: "A hierarquia católica representa uma grande mea culpa: se se difundem cada vez mais práticas esotéricas e seitas satânicas é também culpa sua." (Accattoli 1996:n.p., tradução nossa) ${ }^{21}$.

Nesse sentido, os jornais laicos acabam incorporando alguns elementos da narratividade dos exorcistas ao veicular seus discursos e inserir a leitura diabolizante sobre os novos movimentos religiosos, como New Age, Reiki, satanismo. Quantitativamente pouco significativos no território italiano, os satanismos contemporâneos e as práticas new age tornaram-se alvos recorrentes dos exorcistas e dos grupos católi- 
cos envolvidos nessa perseguição às seitas. Essa trama e esse discurso sobre o "mal do outro", importantes para a legitimação do projeto dos sacerdotes italianos de volta do exorcismo, envolveram estratégias narrativas (produção de uma literatura sobre o tema) e midiáticas (veiculação desses discursos na grande mídia nacional). Afinal, uma volta do exorcismo somente seria possível dentro de uma conjuntura em que o "mal diabólico" fosse também vigente, tornando-se declaradamente um inimigo pouco combatido pela Igreja Católica.

\section{Considerações finais: por trás do olhar diabolizante sobre as alteridades religiosas contemporâneas}

Por que em meio ao contexto do pós-Concílio Vaticano II, especificamente na década 1980, o projeto teológico-político desses exorcistas se embasava ainda em alguns elementos do modelo tridentino de Igreja? Por que havia uma preocupação em conservar esse passado parcialmente questionado e silenciado no Concílio de 1962? Como resposta, a partir do que foi analisado no presente artigo, propomos três possíveis interpretações. A primeira é a de que o Concílio Vaticano II, apesar de não ter reformado toda a tradição da Igreja Católica, modificou muitos dos seus elementos tridentinos, como a centralização, a hierarquização e outros aspectos da "cristandade" da Igreja. No entanto, após o fim do referido evento, houve um lento processo de difusão e apropriação daquilo que havia sido elaborado por diferentes grupos católicos, das comunidades de base à renovação carismática. Ele foi um concílio plural e abriu espaço para diferentes leituras da vida eclesial e religiosa, e nem todas as vertentes se apropriaram de todos os seus preceitos. A segunda explanação é a de que os padres exorcistas empenhados na volta do ofício de expulsar o demônio foram formados culturalmente e religiosamente na conjuntura pré-conciliar, ainda marcada por uma igreja de traços tridentinos e pouco aberta à pluralidade religiosa e cultural. Por último, no período de formação dos referidos sacerdotes, a Itália não vivia um momento de ampla pluralização cultural e de crenças, com exceção das migrações internas, sobretudo do sul ao centro e ao norte do país. A variação cultural trazida pelos "estrangeiros" e a discursividade sobre seitas e novos movimentos religiosos era menor entre as décadas de 1930 e 1960 se comparada ao que começou a emergir nos anos 1980 e 1990. Essa presença significava "dos outros", e a destituição de grande parte do poder público da Igreja não ocorreu sem respostas conservadoras.

Os três exorcistas que escolhemos para analisar como representantes desse projeto teológico-político no âmbito narrativo nasceram em meados da década de 1920: Corrado Balducci, Gabriele Amorth e Raul Salvucci. Logo, receberam uma formação cultural, religiosa e eclesiástica que perpassou as Grandes Guerras, o pós-guerra e o advento da Democracia Cristã na Itália. A formação ocorreu em um momento anterior ao Concílio Vaticano II (1962-1965), porém a atuação desses sacerdotes 
transcorreu tanto o período de elaboração e execução conciliar quanto a conjuntura posterior de sua recepção. Isso não nos autoriza a dizer que todos os padres formados e atuantes antes do Vaticano II seguem essa mesma perspectiva, e nem que os padres pós-conciliares tenham adotado uma postura exclusivamente pós-vaticanista. Até porque o referido evento foi organizado e desenvolvido por uma maioria de bispos formados, anteriormente, em caráter marcadamente tridentino e em diálogo maior com o Concílio Vaticano I (Martina 2014:290).

Esses exorcistas formaram-se e construíram boa parte da leitura que fazem da Igreja em um momento em que a instituição usufruía de um espaço social e político mais forte e atuante na sociedade italiana, diferentemente do que foi surgindo a partir da década de 1970 com os referendos sobre divórcio e aborto, e em 1984 com a desvinculação eclesiástica do Estado e com o início da pluralização religiosa e cultural mais significativa do território nacional (Martina 2014:354). A fé cada vez menos institucional e mais cultural, menos dependente dos preceitos defendidos pela Igreja Católica e mais atenta aos desejos individuais (Garelli 2012), não foi recebida de forma positiva por esses padres que, de certa forma, resistem em aceitar muitos dos aspectos do Vaticano II no que tange, sobretudo, à pluralidade religiosa, à preocupação social e à releitura de alguns aspectos "sobrenaturais" como a noção de diabo (mal), exorcismo e possessão.

Apesar de não visualizarmos uma relação causal entre esses aspectos formativos, notamos que existe uma certa nostalgia de um passado da Igreja no discurso desses exorcistas e uma dificuldade em dialogar com a pluralidade religiosa na Itália e no mundo. Retomar o exorcismo, além de ser um caminho pastoral de reintegração do fiel à vida institucional e de "cura" para muitos problemas pessoais, seria um modo de trazer, ainda que minimamente, a autoridade e a centralidade da Igreja no combate ao "mal", interpretado por eles de maneira sobrenaturalista, ou seja, na atuação real da presença demoníaca. Como especifica Franco Garelli, "Em alguns ambientes eclesiásticos é forte a nostalgia do passado, quando os valores e o ponto de vista dos católicos (também graças ao peso da Democracia Cristã) tinham maior importância na sociedade" (Garelli 2003:15-16).

Por tratar-se de um tema da história recente italiana, não podemos concluir este artigo de forma totalizante. $\mathrm{O}$ recorte temporal estudado aborda o período de consolidação e expansão do projeto teológico-político de retomada do exorcismo na Itália e suas rivalidades com os NMR, porém não elenca os desdobramentos desse revival após a efetivação dessa empreitada. Nesse sentido, abre-se um novo espaço para analisar o que vem após esse período de concretização de ideias que estavam sendo elaboradas desde as décadas de 1970 e 1980. Esse projeto de retomada tem como localidade privilegiada e inicial o território italiano, entretanto, não se restringe a ele. Há uma conexão entre o que foi desenvolvido na Itália com os outros países da Europa e mesmo da América. Nessas outras localidades, as minorias religiosas ainda se constituem como um problema para os padres empenhados em "expulsar o mal". 


\section{Referências Bibliográficas}

ALMEIDA, João Carlos; MANZINI, Rosana; MAÇANEIRO, Marcial (org.). (2013), As janelas do Vaticano II: a Igreja em diálogo com o mundo. Aparecida: Editora Santuário.

AMARAL, Leila. (2000), Carnaval da alma: comunidade, essência e sincretismo na nova era. Petrópolis: Vozes.

BERZANO, Luigi. (2010), New age. Bologna: Il Mulino, Kindle edition.

CLARK, Stuart. (2006), Pensando com demônios: a ideia de bruxaria no princípio da Europa moderna. São Paulo: Edusp.

DE CERTEAU, Michel. (1998), A invenção do cotidiano: artes de fazer. Petrópolis: Editora Vozes, 3a ed.

FILORAMO, Giovanni. (1999), Millenarismo e New age: apocalisse e religiosità alternativa. Bari: Dedalo.

GARELLI, Franco (a cura di). (2003), Sfide per la Chiesa del nuovo secolo: indagine sul clero in Italia. Bologna: Il Mulino.

GARELLI, Franco. (2006), L'Italia cattolica nell'epoca del pluralismo. Bologna: Il Mulino.

GARELLI, Franco. (2012), Religione all'italiana: L'anima del paese messa a nudo. Bologna: il Mulino, Kindle Edition.

GARELLI, Franco. (2016), Piccoli atei crescono: Davvero una generazione senza Dio? Bologna: il Mulino, Kindle Edition.

GATTO TROCCHI, Cecilia. (1996), Il risorgimento esoterico: storia esoterica d'Italia, da Mazzini ai giorni nostri. Milano: Mondadori.

GATTO TROCCHI, Cecilia. (1998), Nomadi spirituali: mappa dei culti del nuovo millennio. Milano: Mondadori.

INTROVIGNE, Massimo; ZOCCATELLI, Pierluigi. (2017), "Il pluralismo religioso italiano nel contesto postmoderno". Le religioni in Italia, 2017. Disponível em: http://www.cesnur.com/il-pluralismoreligioso-italiano-nel-contesto-postmoderno-2/. Acesso em: 02/10/2017.

INTROVIGNE, Massimo; ZOCCATELLI, Pierluigi. (2018a), "Il pluralismo religioso italiano nel contesto postmoderno". Le religioni in Italia, 2018. Disponível em: http://www.cesnur.com/ilpluralismo-religioso-italiano-nel-contesto-postmoderno-2/. Acesso em: 20/11/2018.

INTROVIGNE, Massimo; ZOCCATELLI, Pierluigi. (2018b), "Il Next Age". Le religioni in Italia, 2018. Disponível em: http:/www.cesnur.com/il-pluralismo-religioso-italiano-nel-contestopostmoderno-2/. Acesso em: 07/12/2018.

ISTAT. (2015), Statistiche report - Appartenenza e pratica religiosa, Anno 2011-2012. Disponível em: www.istat.it. Acesso em: 02/10/2018.

MARTINA, Giacomo. (2014), História da Igreja: de Lutero a nossos dias. IV - A era contemporânea. São Paulo: Edições Loyola, 3ㄹ ed.

MARZANO, Marco; UBINATI, Nadia. (2013), Missione impossibile: La riconquista cattolica della sfera pubblica. Bologna: Il Mulino, Kindle edition.

PACE, Enzo. (2003), "La modernizzazione religiosa del cattolicesimo italiano". Il Mulino, no 5: 823-831.

PACE, Enzo. (2011a), "La nuova geografia socio-religiosa in Europa: linee di ricerca e problemi di metodo". Quaderni di Sociologia, 55: n.p. Disponível em: https://journals.openedition.org/qds/649. Acesso em: 12/06/2018.

PACE, Enzo. (2011b), Vecchi e nuovi dei: la geografia religiosa dell'Italia che cambia. Milano: Paoline.

PACE, Enzo. (2014), "Increasing religious diversity in a society monopolized by Catholicism". In: G. Giordan; E. Pace (ed.). Religious Pluralism: Framing Religious Diversity in the Contemporary World. Cham: Springer.

PIRES, Tiago. (2014), O pastor das almas: José Silvério Horta e a construção cultural de um sacerdote exemplar. Campinas: Dissertação de Mestrado em História, UNICAMP.

YOUNG, Francis. (2016), A history of exorcism in Catholic Christianity. London: Palgrave. 


\section{Fontes}

\section{Artigos de revista da renovação carismática na Itália}

GASPERONI, Antonella. (2000), "New Age o Fede Cristiana". Rivista Gesù Risorto, ano VII, no 2, jun. 2000. Arquivo da Biblioteca Central Nacional de Roma.

RIVISTA GESÙ RISORTO. (2002), "Il Reiki”. Rivista Gesù Risorto, ano IX, no 3, set. 2002, p. 16. Arquivo da Biblioteca Central Nacional de Roma.

SUlPASSO, M. (2002), "La posizione della Chiesa". Rivista Gesù Risorto, ano IX, no 3, 2002, p. 17. Arquivo da Biblioteca Central Nacional de Roma.

\section{Artigos de jornais italianos}

ACCATTOLI, Luigi. (1996), "L'esorcista: il satanismo anche colpa della Chiesa". Corriere della Sera, 3 fev. 1996. Arquivo online.

DEL BOCA, Lorenzo. (1984), "Mamma Ebe sgrana il rosario rimpiangendo il regno di miliardi". La Stampa, no 106, 16 abr. 1984, p. 8. Arquivo online.

LA STAMPA. (1984), "Oggi pomeriggio il confronto". La Stampa, no 76, 16 mar. 1984. Arquivo online.

LA STAMPA. (1992), "C’è Satana al telefono, fate venire gli esorcisti”. La Stampa, no 130, 14 maio 1992, p. 16. Arquivo online.

\section{Livros publicados por exorcistas italianos}

AMORTH, Gabriele. (2010 [1996]), Exorcistas e psiquiatras. São Paulo: Palavra \& Prece, 3a ed.

AMORTH, Gabriele. (2013 [2010]), Memorie di un esorcista: la mia vita in lotta contro Satana. Milano: PickWick.

AMORTH, Gabriele. (2014 [1990]), Um exorcista conta-nos. Lisboa: Paulinas, 9aㅡ ed.

BALDUCCI, Corrado. (1974), A possessão diabólica. Lisboa: Editora Ulisseia.

BALDUCCI, Corrado. (1991), Adoratori del diavolo e rock satanico. Casale Monferrato: Piemme.

BALDUCCI, Corrado. (1994), Il diavolo. Cles: Oscar Mondadori.

SALVUCCI, Raul. (2008 [1998]), Le potenze malefiche: come operano, come si combattono. Camerata Picena: Editrice Shalom.

SALVUCCI, Raul. (2016 [1992]), Cosa fare con questi diavoli? Indicazioni pastorali di un esorcista. Milano: Ancora.

\section{Documentos eclesiásticos}

CONFERENZA EPISCOPALE ITALIANA. (1993), "Limpegno pastorale della Chiesa di fronte ai nuovi movimenti religiosi e alle sette". Nota pastorale del segretariato per l'ecumenismo e il dialogo. Notiziario della Conferenza Episcopale Italiana, n 7, jun. 1993, p. 178-213. Disponível em: https://www. chiesacattolica.it/wp-content/uploads/sites/31/2017/02/Nuovi_movimenti_e_sette_Nota.30.05.93. pdf. Acesso em: 06/03/2019.

COSTA, Lourenço (org.). (2007), Documentos do Concilio Ecumênico Vaticano II: (1962-1965). São Paulo: Paulus, 4를. 
Religião e Sociedade, Rio de Janeiro, 40(1): 179-202, 2020

\section{Notas}

1 Pesquisa financiada pela Fundação de Amparo à Pesquisa do Estado de São Paulo (FAPESP) - processo no 2015/02226-1.

2 Existe uma extensa literatura sobre exorcismo e possessão produzida na Itália por exorcistas católicos, sobretudo a partir dos anos 1980. Os sacerdotes citados neste artigo fazem parte desse grupo de exorcistas-autores.

3 Categoria utilizada por Enzo Pace para definir as mudanças no catolicismo italiano após o Concílio Vaticano II, especialmente a partir dos anos 1990 (Pace 2003).

4 Criada em Roma em 1991, tendo como figura central a presença do exorcista italiano Gabriele Amorth.

5 No original: "Purtroppo in questi ultimi decenni dovevamo assistere anche a una negazione del genere, quale assaggio di una vasta crisi dottrinale che sta imperversando tra il clero. Specie infatti nel periodo post-conciliare si è andata formando una corrente teologica, che pur in aperto contrasto con l'insegnamento biblico, con il Magistero Ecclesiastico e con il comune sentire di sempre va affermando e propagandando la morte di satana. [...] Ed eccolo il libro sul diavolo. Esso ha principalmente un duplice scopo: riaffermare l'esistenza; vedere poi come lo si possa riconoscere presente la sua attività malefica".

6 No original: "Fino ai giorni del Concilio Vaticano II, quando si diceva ancora la Mesa in latino, i sacerdoti al termine della Messa dicevano una preghiera a san Michele: "Respingi nell'inferno satana e gli altri spiriti maligni che vanno vagando per il mondo". Poi questa preghiera è stata abolita quasi per chiudere l'ombrello, proprio mentre cominciava l'alluvione della presenza di satana nella nostra società. Questa è la presenza ordinaria".

7 No original: "Questa società, che affoga ormai nella piatta realtà materialistica, cerca compensazione al bisogno di valori di ordine spirituale con le più svariate forme di contatto con l'occulto. [...] Se la Chiesa volesse, attraverso gli insegnanti di religioni, potrebbe avere una documentazione valida sull'orientamento della nuova generazione verso queste esperienze: ma, probabilmente, queste cose è più comodo ignorare".

8 No original: "[...] l'Italia sta diventando una società caratterizzata da una diversità religiosa molto articolata $\mathrm{e}$ perciò del tutto inedita".

9 "C'è Satana al telefono, fate venire gli esorcisti". La Stampa, no 130, 14 maio 1992, p. 16. Arquivo da Biblioteca Nacional Central de Roma. No original: "Lesperienza gli ha insegnato ad accettare come reali fenomeni non giustificabili razionalmente. E a scoprire che, spesso, i disagi psichici si sommano agli effetti di presenze malefiche. Padre Candido - ricorda - per arrivare alla diagnosi a volte si faceva affiancare da uno psichiatra. Molti fattori - insiste - incoraggiano il maligno: 'La fede che vacilla, il materialismo, il consumismo, il diffondersi, specie fra i giovani, delle pratiche di spiritismo, magia, occultismo"'.

10 No original: "Nelle retoriche politiche delle destre etno-nazionaliste europee, che tendono a stigmatizzare come l'unico vero nemico della civiltà europea sia l'islam, il richiamo alla difesa dell'identità cristiana suona ambiguo: il cristianesimo di cui si parla è, in realtà, la cifra simbolica che rivela la pulsione ideologica alla pulizia etnica di un'Europa che appare ai loro occhi decadente, contaminata da religioni barbare, estranee e pericolose. È il segno della difficoltà crescente da parte di una quota consistente di europei nell'accettare l'inedito pluralismo religioso che si va profilando nelle nostre società del Vecchio Continente".

11 Categoria utilizada pela antropóloga italiana Cecilia Gatto Trocchi em seu livro Nomadi spirituali (Gatto Trocchi 1998).

12 Para entender melhor essa relação entre New Age e milenarismo, consultar a obra de Giovanni Filoramo (1999).

13 "La posizione della Chiesa". Rivista Gesù Risorto, ano IX, no 3, p. 17. Arquivo da Biblioteca Central Nacional de Roma.

14 No original: "La risposta cristiana al New Age è contenuta nel mistero dell'Incarnazione: il Figlio di Dio è nato dalla Vergine Maria 'per salvarci'. In nessun altro nome c'è salvezza (cf. At 4, 12). Nessuno può salvarsi da solo, con tecniche umane. [...] Il cristiano aderisce non ad un salvatore di invenzione umana, ma al Gesù Cristo del Vangelo, che ci salva attraverso la croce e la risurrezione, ci propone la via delle beatitudini e ci fa trascendere, pur illuminandolo e promuovendolo, l'orizzonte terreno.".

15 "New Age o Fede Cristiana". Rivista Gesù Risorto, ano VII, no 2, jun. Arquivo da Biblioteca Central Nacional de Roma. No original: "Tenendo conto che le basi della dottrina New Age non possono proprio coesistere con la fede cristiana, c'è da dire che questa 'religiosità', basata essenzialmente sulle potenzialità umane, convince insidiosamente quelli che vogliono sempre far parte del cerchio dei 'pochi', quelli inquieti sempre in cerca di qualcosa di nuovo da abbracciare e qualcosa di giusto per cui 'combattere', e lo fa ponendosi come messaggio di pace e di armonia universale".

16 No original: "La società può anche andare alla rovina: ma la singola persona che ha accesso a determinate tecniche entrerà comunque in una sua età dell'oro personalissima e privata". 
17 Segundo a estimativa do CESNUR de 2016 (Introvigne \& Zoccatelli 2017).

18 Conferir o seguinte artigo da revista carismática católica italiana: "Il Reiki". Rivista Gesù Risorto, ano IX, no 3, set. 2002, p. 16. Arquivo da Biblioteca Central Nacional de Roma.

19 Cf. "Mamma Ebe sgrana il rosario rimpiangendo il regno di miliardi". La Stampa, no 106, 16 abr. 1984.

20 Cf. "Oggi pomeriggio il confronto". La Stampa, no 76, 16 mar. 1984, p. 3.

21 "Lesorcista: il satanismo anche colpa della Chiesa". Corriere della Sera, 3 fev. 1996. No original: "Non ci sono sacerdoti preparati in tema di culti satanici', aveva detto Balducci: 'Pochi si interessano alla demonologia, alla parapsicologia e alla psichiatria'. Ed ecco la denuncia del padre Amorth, paolino ed esorcista della diocesi di Roma: 'La gerarchia cattolica recitare un grosso mea culpa: se si diffondono sempre più pratiche esoteriche e sette sataniche è anche colpa sua”".

Submetido em: 21.03.2019

Aceito em: 08.04.2020

Tiago Pires*(tiago_pires@ymail.com)

* Doutor em História pela Universidade Estadual de Campinas (UNICAMP), Campinas, SP, Brasil. 


\section{Resumo:}

\section{Os perigos do outro: minorias religiosas e resistência tridentina dos exorcistas italianos}

Os movimentos de resistência à pluralidade religiosa perpassam toda a história da Igreja Católica, que abarca desde o início a dificuldade em dialogar com as alteridades nas formas de crer. Para este artigo, temos como recorte a conjuntura que se formou após os desdobramentos do Concílio Vaticano II, especificamente a sociedade italiana a partir dos anos 1980. Nosso objetivo consiste na análise de uma vertente singular dessa resistência "tridentina", concatenada no projeto teológico-político empreendido por exorcistas italianos. Embasamo-nos no estudo das discursividades produzidas por alguns sacerdotes em suas narrativas, publicadas em diferentes plataformas culturais. Entendemos, portanto, a "rivalidade" entre exorcistas e minorias religiosas na Itália como um embate que está para além do campo teológico-religioso, configurando-se também como uma disputa política.

Palavras-chave: Pluralidade religiosa; História da Itália; Catolicismo; Minorias religiosas; Exorcismo

\section{Abstract:}

\section{The dangers of the "other": religious minorities and "Tridentine" resistance of Italian exorcists}

The movements of resistance to religious plurality cross the history of Catholic Church, which incorporates from the beginning the difficulty in dialogue with other forms of believing. For this article, we selected the conjuncture that was formed after the unfolding of the Second Vatican Council, specifically the Italian society from the 1980s. Our goal is to analyze a specific group of this "conservative" resistance, contained in the theological-political project undertaken by Italian exorcists. We base our study on the discourses produced by some priests in their narratives, published on different cultural platforms. In this sense, we understand the rivalry between exorcists and religious minorities in Italy as a conflict that goes beyond the religious-theological field, also being arranged as a political dispute.

Keywords: Religious plurality; History of Italy; Catholicism; Religious Minorities; Exorcism 